\title{
Paradoxical Bactericidal Effects of Hydrophobic Lung Surfactant Proteins and Their Peptide Mimics Using Liposome Molecular Trojan
}

\author{
Kunal Dutta ${ }^{1,4}$, Kaushik $\mathrm{Nag}^{2}$, Valerie Booth², Erin Smyth², Helen Dueck², \\ Mauricia Fritzen-Garcia ${ }^{3}$, Chandradipa Ghosh ${ }^{1}$, and Amiya Kumar Panda ${ }^{4 *}$ \\ ${ }^{1}$ Microbiology and Immunology Laboratory, Department of Human Physiology with Community Health, Vidyasagar University, \\ Midnapore -721 102, West Bengal, INDIA \\ ${ }^{2}$ Department of Biochemistry, Memorial University of Newfoundland, St. John's, Newfoundland, CANADA \\ ${ }^{3}$ Federal University of Pana, Aquaculture Lab, CEP 83255-000, BRAZIL \\ ${ }^{4}$ Department of Chemistry and Chemical Technology, Vidyasagar University, Midnapore -721 102, West Bengal, INDIA
}

\begin{abstract}
Lung surfactant, besides alveolar stability, also provides defence against pathogens by surfactant proteins (SP), SP-A and SP-D. The hydrophobic proteins SP-B and SP-C enhance surface activity. An unusual and paradoxical effect of bovine LS and synthetic model LS with SP-B/-C was bactericidal to Staphylococcus aureus and Escherichia coli. Bacterial proliferation were investigated with bovine lung surfactant extract (BLES), dipalmitoylphosphatdylcholine, palmitooleylglycerol, in combination with SP$\mathrm{B} /-\mathrm{C}$ using standard microbiological colony forming unit (CFU) counts and structural imaging. BLES and other surfactant-SP-B/-C mixtures inhibit bacterial growth in the concentration range of $0-7.5 \mathrm{mg} / \mathrm{mL}$, at > $10 \mathrm{mg} / \mathrm{mL}$ paradoxical growth of both the bacterial species suggest antibiotic resistance. The lipid only LS

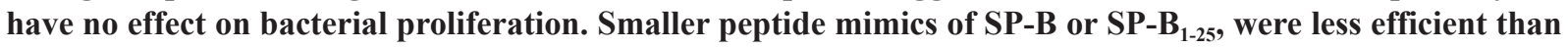
SP- $C_{f f}$. Ultra structural studies of the bacterial CFU using electron and atomic force microscopy suggest some membrane damage of $S$. aereus at inhibitory concentration of BLES, and some structural alteration of $E$. coli at dividing zones, suggesting utilization and incorporation of surfactant lipid species by both bacteria. The results depicted from in vitro studies are also in agreement with protein-protein interactions obtained from PatchDock, FireDock and ClasPro algorithm. The MD-simulation decipher a small range fluctuation of gyration radius of the LS proteins and their peptide mimics. The studies have alarming implications in the use of high dosages $(100 \mathrm{mg} / \mathrm{mL} / \mathrm{kg}$ body weight) of exogenous surfactant for treatment of respiratory distress syndrome, genetic knock-out abnormalities associated with these proteins, and the novel roles played by SP-B/C as bactericidal agents.
\end{abstract}

Key words: lung surfactant proteins, bactericidal activity, TEM, AFM, peptide docking

\section{INTRODUCTION}

Pulmonary or lung surfactant (LS) secreted by type-II pneumocytes at the lung air-alveolar fluid interface is primarily responsible for terminal air-way stability during normal respiration. Formation of surface active film by LS reduces the surface tension of the lung air-water interface at end expiration to very low values $(1-2 \mathrm{mN} / \mathrm{m})$, preventing alveolar collapse. Among the other lipids, PS is mainly enriched with 1,2-dipalmitoylphosphatidylcholine (DPPC) and phosphatidylglycerol(PG), not normally found in most eukaryotic cell membranes. LS also consists of about 10 wt\% surfactant protein (hydrophilic: SP-A and SP-D; hydrophobic: SP-B and SP-C). Despite the main "surface active" function of the material in the lungs, certain lipid and protein components of LS have been shown to play major roles in the immune functions.

A series of systematic genetic knock-out (KO) studies of SP-A, SP-B, SP-C and SP-D over a decade ${ }^{1)}$. have enhanced the overall understanding as well as challenged classical ideas of the role of these proteins in surfactant or the major role of LS merely as "surface active agent". Only SP-B knock-out has been shown to be fatal, while SP-C

\footnotetext{
*Correspondence to: Amiya Kumar Panda, Department of Chemistry and Chemical Technology, Vidyasagar University, Midnapore -721 102, West Bengal, INDIA

E-mail: akpanda@mail.vidyasagar.ac.in

Accepted April 12, 2018 (received for review February 12, 2018)

Journal of Oleo Science ISSN 1345-8957 print / ISSN 1347-3352 online

http://www.jstage.jst.go.jp/browse/jos/ http://mc.manusriptcentral.com/jjocs
} 


\section{K. Dutta, K. Nag, V. Booth et al.}

does not seem to significantly alter the surface activity of the material under in vitro conditions. However, the SP-B and SP-C knock-out animals show higher susceptibility to bacterial infections, also in such cases other lung diseases can develop. Available literature reports suggest that SP-C-KO mice become susceptible to pathogenic challenges, since the protein can bind and may sequester bacterial lipopolysaccharides (LPS ${ }^{2)}$. These animals may develop conditions linked to interstitial lung disease (ILD) and idiopathic interstitial pneumonia ${ }^{3)}$. The studies have brought about a paradigm shift in the understanding of the complex nature of the "surface active agent" at the lung air-water interface, and possible roles of the hydrophobic proteins in vivo beyond surface activity is not unwarranted, especially in the light of the knock-out studies. The hydrophobic proteins of LS from most mammalian species are highly conserved $^{4)}$. SP-B has structural homology with saposins which belong to the ameophore superfamily ${ }^{5)}$. The amphipathic helices of SP-B favourites association with lipid headgroups of the membrane bilayer ${ }^{1,6)}$ and especially with the charged phospholipids such as phosphatidylglycerol $(\mathrm{PG})$, found in a number of bacterial species as well as in significant amounts in LS, not in any other eukaryotic membranes $^{7)}$. SP-B-PG interactions induce fusion of bilayer membranes ${ }^{8)}$, although the implication of such fusogenic properties have been attributed to extracelluar transformations of LS into specific morphological forms, viz., tubular myelin formation ${ }^{9)}$. Highly hydrophobic SP-C is an acylated lipo-peptide with one or two palmitoyl fatty acids attached to its terminal cysteines, and can fit into the bilayer membranes as trans-membrane protein and antibiotic peptide ${ }^{10)}$. Dimeric form of SP-C can form porin type structures in bilayer membranes ${ }^{11)}$.

Various pulmonary diseases occur either due to insufficient LS, or inhibition of the surfactant function by proteins, other than the SPs (e.g., serum proteins). Insufficient secretion of LS in neonates cause respiratory distress syndrome (RDS) in preterm infants, and acute-RDS (ARDS) in adults develop due to the inhibition of LS by leaked haematological materials into the alveolar airspaces ${ }^{12)}$. Dysfunction of the LS systems have been shown to be related to diseases such as cystic fibrosis, pneumonia, chronic bronchitis, and others which occur because of acquired immune deficiency syndrome(AIDS) ${ }^{13)}$. Pulmonary inflammation also is an important factor in the patho-physiology of surfactant dysfunction. Inflammation may occur due to alveolar epithelial contact with bacterial antigens, allergens, inhaled or aspirated agents. Microorganisms can also cause multiple types of lung and connatal infections such as that found in pneumonia and in the early onset of neonatal septicemia. Group B Streptococci(GBS), Staphylococcus aureus and Escherichia coli are often involved in this connatal infection. Enterococcus, Pseudomonas aeruginosa and Haemophilus influenzae lead to specific type of infections in adults ${ }^{14)}$. Lung lavage fluids as well as some exogenous surfactants show contradictory bactericidal effects against certain bacterial species (Group-B Streptococci) while not the others (E. coli and $S$. aureus). SP-A and SP-D, the large ( $400 \mathrm{kDa})$ hydrophilic glycoproteins of the lectin superfamily, bind pathogens via their carbohydrate recognition domains for presentation to lung macrophages. However, they are removed from all exogenous and semi-synthetic preparations used for clinical therapy in RDS and ARDS. Most replacement surfactants, although contain SP-B and SP-C, not only enhance surface activity of LS lipids (as such roles are laboratory assigned from in vitro studies $)^{15)}$, but also removed inhibition of LS activity caused to serum protein in ARDS type situation ${ }^{16)}$. The smaller hydrophobic SP-B(17.4 kDa dimer)and SP-C (4.2 kDa, acylated monomer) may have some yet unknown functions beyond surface activity as some unique properties of these are being discovered. Studies have shown that SP-C can bind to specific bacterial phospholipids ${ }^{17)}$, and exhibit cationic channel activity when inserted in planar surfactant lipid bilayer ${ }^{18)}$. SP-B also shares structural homology to a number of pore forming proteins and has been classified to belong to the ameobapore superfamily of proteins ${ }^{19)}$. Previous study reported possible mechanism of biophysical interaction leading to inactivation of the $\mathrm{LS}^{20)}$. In addition, a number of systematic studies suggest that natural or semi-synthetic exogenous surfactants consisting SP-B/-C influence proliferation of certain bacteria ${ }^{21,22)}$. However, in case of in vivo studies, where the clinical surfactant and a thousandfold increase of bacteria was instilled directly in the lungs, the replacement of surfactant exhibited bactericidal effect ${ }^{23)}$. To the best of our knowledge, in vitro studies on the bactericidal effects of SP-B/-C are not abundant in the literature.

However, in a recent study, the exact mode of the antimicrobial peptides (AMPs) has been enlightened that suggests peptides induce membrane stress leading to lethal disruption of the cell membrane ${ }^{24)}$. The outer membrane proteins are essential for bacterial survival and its play an important role to trigger specific immunological respons$\mathrm{es}^{25)}$. Therefore, we have performed a detailed in silico analysis of the LS proteins and their peptide mimics to predict its functionality and mode of action before going into the in-depth in vitro study. The backbone stability is an important property of any AMPs to cast a long shadow on host immune system ${ }^{26)}$. Thus, we have performed the molecular dynamic simulation of the LS proteins and their mimics in cubic water box followed by protein-protein interaction (PPI) study using ambiguous docking algorithms.

In the present study, the influence of a clinically used bovine lipid extract surfactant (BLES), which contains the normal amount of LS lipids and SP-B and SP-C as in most lavaged mammalian surfactant, on the proliferation of $E$. coli (gram-negative bacteria) and $S$. aureus (gram-positive 
bacteria) have been reported. Both the species are known for the early onset of neonatal infection and diseases ${ }^{27)}$. Earlier studies failed to conclude whether the lipids and/or the SP-B/-C of LS had any specific effects on bacteria. Thus the model LS componential mixtures of dipalmitoylphsophatidylcholine (DPPC), DPPC + palmitooleylphosphatidylglycerol (POPG) mixture with different amounts of SP-B, SP-C, and their peptide mimics SP-B1-25 and SP- $\mathrm{C}_{f f}$ were also explored ${ }^{28)}$. Dose dependent response of different concentration ranges (used previously by others, 5-20 mg/ $\mathrm{mL}$; as well as smaller amounts, $0.1-7 \mathrm{mg} / \mathrm{mL}$ ), LS containing the hydrophobic proteins were studied separately. Previous studies ${ }^{29)}$ have shown that different types of antibiotics and peptides are inhibitory to bacterial species over a narrow concentration range considered as an antibiotic resistance linked to complex proliferation and growth cycles of bacteria controlled at the genetic level ${ }^{30}$. The paradoxical effect of high concentration of BLES suggest that the surfactant can be utilized as nutrients for the bacteria, as well as antimicrobial resistance or the paradoxical "Eagle effect" ${ }^{31}$ is also seen with the SP-B/-C acting as antibiotics. Structural studies using electron microscopy (TEM / SEM) and atomic force microscopy (AFM) allow the observation of the surface topography of biological samples at the nanometer resolutions. Combined TEM/SEM and AFM studies are expected to provide further information on the incorporation of surfactant materials as possible nutrients for the bacteria. It is expected that such studies would shed further light on the alarming implications in the life saving therapeutic interventions of high dosage of clinical LS on bacterial proliferations in the diseased lung.

\section{Materials and Methods \\ 2.1 Materials}

The bacterial strains Escherichia coli 25250 and Staphylococcus aureus 6020 were obtained from the American type culture collection (ATCC, Rockville, MD, USA). Bovine lipid extract surfactant $\left(\mathrm{BLES}^{\mathrm{TM}}\right)$ was obtained from BLES Biochemical Inc. (London, Ontario, Canada) as $5 \mathrm{~mL}$ vial with a stated phospholipid concentration of $27 \mathrm{mg} / \mathrm{mL}$, as used in standard dosage allowed for clinical instiallations as replacement surfactant treatments. 1,2-dipalmitoyl-snglycero-3-phosphatidylcholine (DPPC) and 1-palmitoyl2-oleoyl-sn-glycero-3-[phosphor-rac-(1-glycerol)] sodium salt (POPG) were purchased from Avanti Polar Lipids (Alabaster, AL, USA). HPLC grade chloroform and methanol were purchased from Fisher Scientific (Ottawa, ON, Canada). Bacto ${ }^{\mathrm{TM}}$ tryptic soy broth and Difco ${ }^{\mathrm{TM}}$ tryptic soy agar(Becton, Dickinson and Company Sparks, MD) were purchased from their Canadian subsidiary (Fisher Scientific, Ottawa, ON). Sodium chloride, ACS reagent $(\geq 99 \%)$, 2,2,2-trifluoroethanol (TFE) and 1,1,1,3,3,3-hexafluoro- 2-propanol (hexafluoroisopropanol, HFIP) were purchased from Sigma-Aldrich Chemicals (St. Louis, MO, USA). Surfactant proteins-B and -C were extracted from porcine lung lavage by methods discussed in details elsewhere ${ }^{32}$. The synthetic peptides SP-B ${ }_{1-25}$ and SP-C $_{f f}$ were obtained synthesized by methods discussed in details previously ${ }^{32}$. Primary structures of the peptides, used in the present set of studies, are shown in Fig. 1.

\subsection{Bacterial Strains and Culture Condition}

The Escherichia coli ATCC 25250 and Staphylococcus aureus ATCC 6020 strains were stored at $5{ }^{\circ} \mathrm{C}$ in tyrptic soy agar(TSA) containing a solution of pancreatic digest of casein $15 \mathrm{~g} / \mathrm{L}$, enzymatic digest of soybean meal $5 \mathrm{~g} / \mathrm{L}$, sodium chloride $5 \mathrm{~g} / \mathrm{L}$ and agar $15 \mathrm{~g} / \mathrm{L}$ (Merck, USA). Before use, one colony of bacteria was transferred to $5 \mathrm{~mL}$ tryptic soy broth (TSB) composed of the following: pancreatic digest of casein $17.0 \mathrm{~g} / \mathrm{L}$, enzymatic digest of soybean meal $3.0 \mathrm{~g} / \mathrm{L}$, dextrose $2.5 \mathrm{~g} / \mathrm{L}$, sodium chloride $5.0 \mathrm{~g} / \mathrm{L}$, and potassium phosphate $2.5 \mathrm{~g} / \mathrm{L}$, and was cultured for 24 hours at $37^{\circ} \mathrm{C}$. Bacterial suspensions were diluted to desired concentration by measurements of the optical density of the suspensions at $600 \mathrm{~nm}$ using a spectrophotometer (UV 260, Shimadzu, Japan) with reference to standard values established by a ten-fold dilutions of the suspension on TSA plates. Purity of the working culture was determined by gram staining ${ }^{33)}$.

\subsection{Bacterial Growth in Surfactant}

Effect of different BLES and model surfactant concentration on the in vitro bacterial growth were determined by incubation of $0.2 \mathrm{~mL}$ of the bacterial working culture with $2 \mathrm{~mL}$ TSB and surfactant. To adjust the dilution of samples to the same final volume desired amount of saline $(0.85 \% \mathrm{NaCl})$ were added. For $E$. coli, the surfactant concentration was in the range of 0 to $2 \mathrm{mg} / \mathrm{mL}$ and for $S$. aureus it was $0-7.5 \mathrm{mg} / \mathrm{mL}$. These concentrations were chosen since it was found that above these concentrations, BLES actually enhanced the growth of both species of bacteria like the previous studies of Rauprich et $a l .{ }^{34)}$ where $5-20 \mathrm{mg} / \mathrm{mL}$ of different replacement surfactant preparations were used. Bacteria-surfactant mixtures were incubated for $24 \mathrm{~h}$ at $37^{\circ} \mathrm{C}$, and the resultant samples were serially diluted tenfold with saline. From the $10^{-6}$ dilution for each sample, $100 \mu \mathrm{L}$ aliquots were spread onto TSA plates for three times. The number of colonies after incubation was counted, and the colony forming units (CFU) per millilitre in the original sample were calculated according to standard microbiological methods discussed elsewhere ${ }^{35}$.

\subsection{Homology Modelling and Structure Validation}

The three-dimensional structure of the hydrophobic lung surfactant proteins and their peptide mimics were constructed using MODELLER $9.19^{36)}$ followed by structure 
1.

(A) EPIPLPYCWLCRALIKRIQAMIPKGALRVAVAQVCRVVPLVAGGICQCLAERYSVILIDTLIGRMLPQLVCRLVLRCS

(B) ERIPLPYCWLCRALIKRIQAMIPKG

(C) LRIPCCPVNLKRLIVVVVVVVLVVVVIVGALIMGI

(D) ERIPEFNLKRLLVVVVVVVLVVVVIVGALIMGI

2.
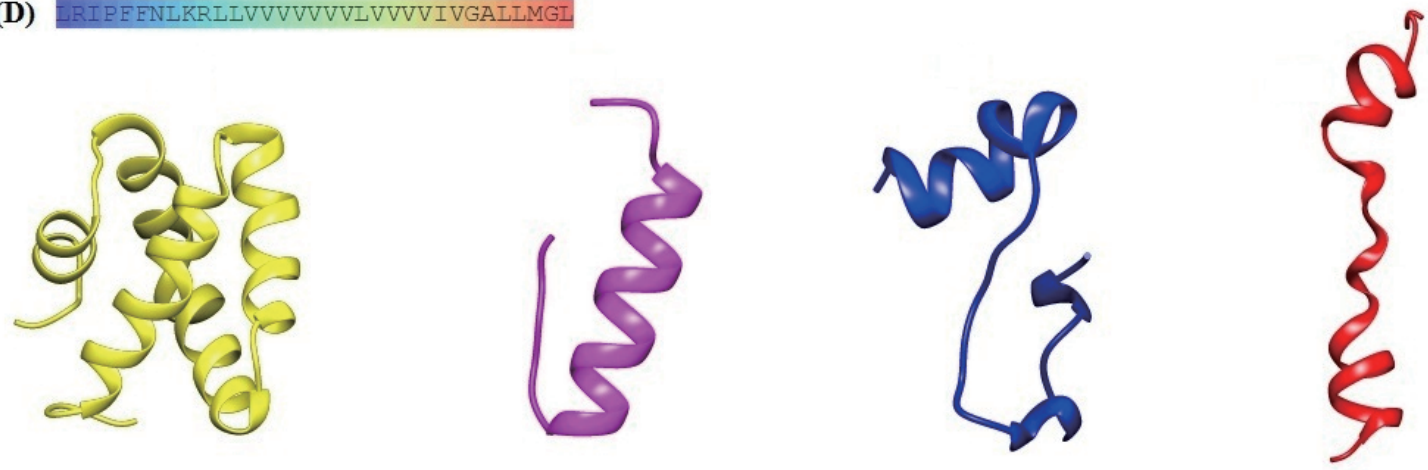

3. Radius of gyration (total and around axes)
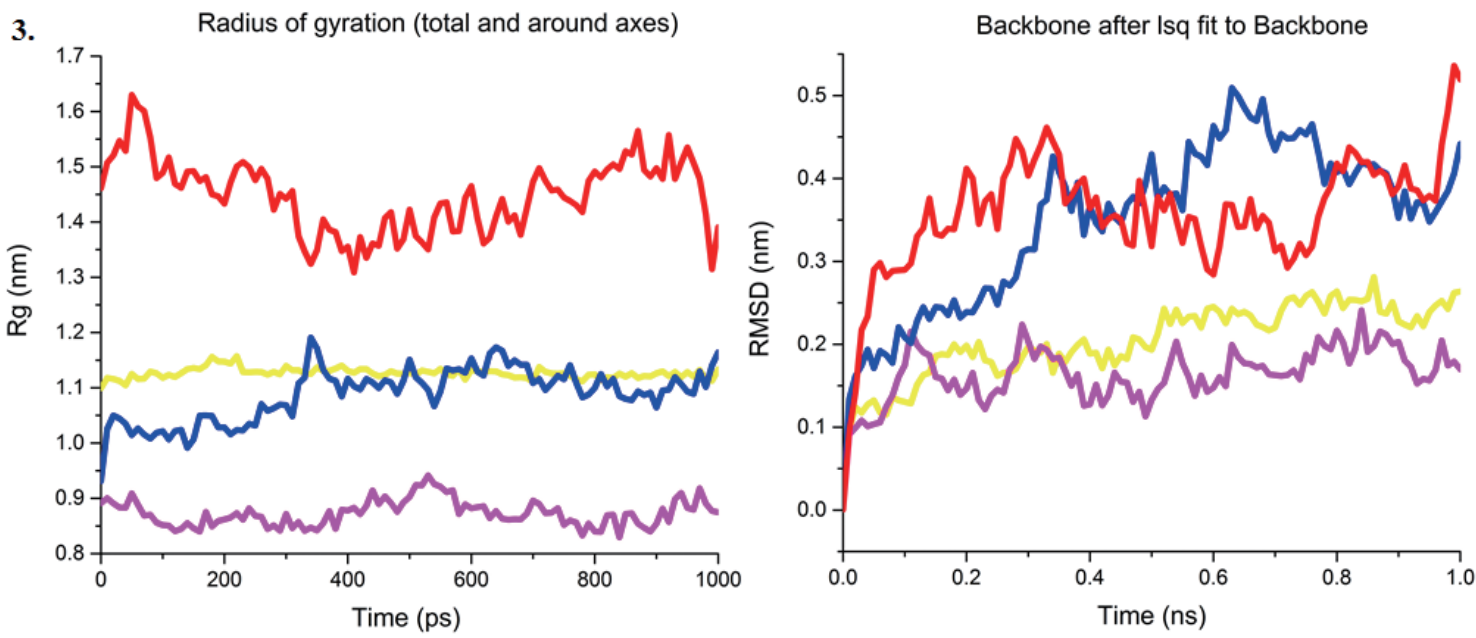

Fig. 1 Three dimensional structures and backbone stability of LS proteins and their peptide mimics. (1), amino acid

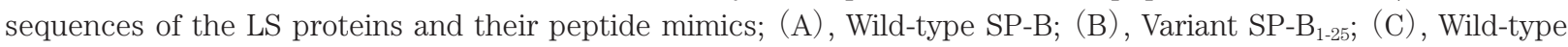
SP-C; (D) Variant SP-C $f f$. (2), three dimensional structures of the LS proteins and their peptides mimics; (3), radius of gyration (total and around axes) and RMSD of backbone after least square fit to backbone of the LS proteins. Yellow , wild-type SP-B; magenta, variant SP-B ${ }_{1-25}$; blue, wild-type SP-C and red, variant SP-C ff $_{\text {. }}$

validation using PROCHECK ${ }^{37)}$.

\subsection{Molecular Dynamics Simulation}

The MD simulation of SP-B/C and their peptide mimics were performed using GROMACS 5.1 ${ }^{38)}$. The Pdb2gmx was used to achieve GROMACS file from protein. The initial protein structure for the simulation was processed using OPLS-AA/L all-atom force field ${ }^{39)}$ and solvated in a cubic box with SPC water molecules maintaining the size at least $2.0 \mathrm{~nm}$ from all atoms as final. To neutralize the net charge on the protein required $\mathrm{Cl}^{-}$ions were added to the cubic water box. The neutralized system was further subjected to energy minimization to remove the irregular torsions, and the process was carried out through the steepest descent minimization algorithm for 50000 steps using 1000 $\mathrm{kJ} / \mathrm{mol} / \mathrm{nm}$ as the maximum force. The two steps equilibra- tion, NVT and NPT were performed for 100 ps before final MD run. The MD simulation was performed for 1000 ps. The graphs obtained were analyzed using xmgrace and the trajectory files were visualized using VMD 1.9.3 ${ }^{40)}$.

\subsection{Protein-Protein Interaction}

The cell surface protein isdA (2o1a), isdC (2q8q) of Staphylococcus aureus and $\beta$-barrel OM proteins bamA (5ekq), lptD (4rhb) of Escherichia coli were taken into account to perform protein-protein interaction (PPI) with LS proteins and their peptide mimics. The PatchDock ${ }^{41)}$, FireDock ${ }^{42)}$ and ClasPro algorithm ${ }^{43)}$ were chosen for PPI study. The best interactive models were visualized using PyMOL $^{44)}$. 


\subsection{Preparation of Model Surfactant Lipid-Hydrophobic Protein/Peptide Dispersions.}

Stock solutions of model surfactants (MS) were prepared with desired amount of DPPC or DPPC:POPG in a 7:3(W/ W) ratio dissolved in chloroform-methanol (3:1, V/V). SP-B and/or SP-C was dissolved in the same solvent and added to the lipid stock solution at 2-8 wt\% to prepare MS preparations of composition close to those of BLES ${ }^{45)}$. In case of peptide incorporation into the MS, the $\mathrm{SP}_{-} \mathrm{B}_{1-25}$ peptide at 4 wt $\%$ and the $\mathrm{SP}_{-\mathrm{C}_{f f}}$ solution were separately added to the DPPC: POPG stock. Details of the peptide synthesis, and methods used to determine accurate concentrations are discussed elsewhere ${ }^{46)}$. The samples were dried under a stream nitrogen gas and were then placed in a vacuum dessicator overnight to remove any traces of solvent. Dried film was then placed under UV light for 20 min to prevent growth of any other possible micro-organisms. Subsequently, the dried material was incubated with $0.9 \%$ saline, heated to $40^{\circ} \mathrm{C}$, and vortexed for 5 min to produce multilamellar dispersion of model surfactant ${ }^{47)}$. Final concentration of the MS dispersions were made close to those of BLES stock solution (27 mg/mL). Transmission electron microscopic (TEM) studies were performed on these dispersions to check for any microbial growth as well as the typical multi-lamellar vesicular dispersions expected from such sample preparations as those for BLES discussed above. Also the MS dispersions were used to a streak plating at $37^{\circ} \mathrm{C}$ for $24 \mathrm{~h}$ to suggest any microbial growth, before performance of TEM considered to be the marker of any microbial contamination during sample preparation.

\subsection{Transmission/Scanning Electron (TEM/SEM) and Atomic Force Microscopic (AFM) Studies}

To gain further insight into the surfactant-bacterial interactions, transmission electron microscopic studies were performed on the BLES, and BLES with bacterial suspension. This was performed from portions of the diluted samples following a $24 \mathrm{~h}$ incubation period at $37^{\circ} \mathrm{C}$ with medium containing $2.0 \mathrm{~mL}$ TSB, $2.0 \mathrm{~mL}$ BLES and $0.5 \mathrm{~mL}$ bacterial culture, used for CFU counts. Control cultures without BLES, $4.0 \mathrm{~mL}$ TSB and $0.5 \mathrm{~mL}$ bacterial suspension were also incubated and prepared for TEM studies ${ }^{48)}$. The samples for TEM studies were fixed with $4 \%$ glutaraldehyde solution, followed by further staining with $6 \%$ osmium tetraoxide. Following $12 \mathrm{~h}$ incubation in the fixative, the samples were pelleted and dehydrated by dilution graded ethanol of 50, 70, 95 and $100 \%$. The dehydrated samples were embedded in EPON812 embedding resin and sectioned into 90-100 nm thin sections via a Reichert Microtome. Finally, uranium acetate and lead citrate stains were applied and the specimens were examined under a Zeiss EM109 TEM and micrographs obtained for at least for five different incubate sections at different magnifications.
SEM studies on the vacuum dried samples were performed using scanning electron microscope (FEI Quanta200 MK2, Oregon, USA). Dried samples were coated with gold by conventional sputtering technique using a gold coater $^{49)}$.

AFM studies were performed on the bacteria-surfactant suspensions placed on freshly cleaved mica substrate to image any surface of outer membrane morphological changes induced by surfactant on the bacteria. The samples were fixed using same methods as with glutraldehyde fixative, without staining ${ }^{50)}$. AFM images of the samples were obtained in contact mode imaging on a Nanoscope IIIa Scanning Probe Microscope(Digital Instruments, CA) using silicon nitride (20 nm) tips. Line section and three dimensional surface topography images were obtained for these samples using the AFM software to suggest any change of surface topology of the outer membranes of the bacteria with and without surfactant.

\subsection{Data Analysis}

All the experiments were performed at least nine times with BLES and independent batches of the bacterial species, and three times with the MS containing hydrophobic proteins and their peptide mimics due to the limited availability of the peptides. The CFU counts were normalized from bacterial growth in TSB being used as 100\% compared to those with surfactant preparations, and displayed by the mean of the data with standard deviations. The statistical significance was compared using a student t-test on the original CFU values as previously performed by others ${ }^{51)}$. No further detailed statistical analysis could be performed due to the smaller number of experiments that was possible with the MS preparations containing the hydrophobic peptides, and to obtain a reasonable comparison of the data between the MS preparations and those of BLES.

\section{Results}

\subsection{Effect of Bacterial LS-Proteins and Peptides on Bac- terial Growth}

Figure 2 displays the effects of the BLES ${ }^{\mathrm{TM}}$ on the in vitro growth of $E$. coli (A) and $S$. aureus (B). Growth of both the bacterial strains were significantly decreased in presence of BLES by about 40-60\% compared to the control experiment. E. coli growth inhibitionby BLES was studied up to $2 \mathrm{mg} / \mathrm{mL}$, and in case of $S$. aureus growth was inhibited up to the concentration of 0.0 to $7.5 \mathrm{mg} / \mathrm{mL}$ of BLES. These concentrations were in accordance with the previous studies ${ }^{52)}$ where it was observed that above 10 $\mathrm{mg} / \mathrm{mL}$ of different surfactant preparations bacterial growth for both species were in fact enhanced instead of growth inhibition. Although the growth inhibition of the 

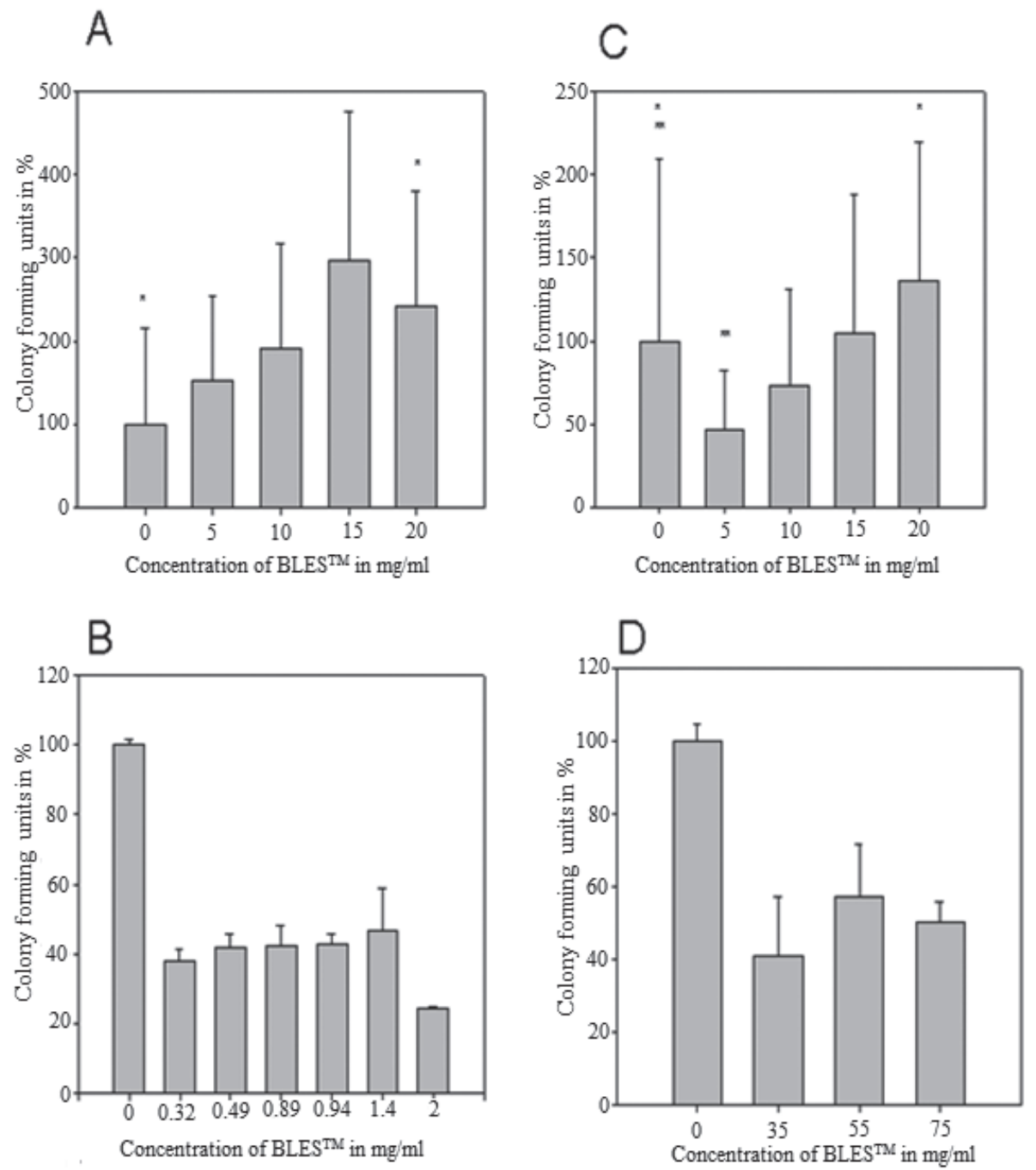

Fig. 2 Antimicrobial effect of BLES ${ }^{\mathrm{TM}}$ on the viability of the gram-negative bacterium $E$. coli $(\mathrm{A}$ and $\mathrm{B})$ and the grampositive bacterium $S$. aureus (C and D) .

bacterial species did not show any general trend of dose dependence upon BLES, the final concentrations of the surfactant were found to be quite replicative within the limits of $1 \mathrm{mg} / \mathrm{mL}$ of BLES.

\subsection{Molecular Dynamics Simulation and Protein-protein interaction}

The results obtained from molecular dynamics simulation depicts small range fluctuation of the gyration radius of the LS proteins and their mimics (Fig. 1). The variation of gyration radius $(\mathrm{Rg})$ was found lowest for Wild-type SP-B $(0.056 \mathrm{~nm})$ with $0.113 \mathrm{~nm}$ as average and it was highest for Variant $\mathrm{SP}_{-} \mathrm{C}_{f f}(0.321 \mathrm{~nm})$ with $0.146 \mathrm{~nm}$ as average and $0.113 \mathrm{~nm}$ (the average value being $0.088 \mathrm{~nm}$ ), $0.250 \mathrm{~nm}$ $\left(0.109 \mathrm{~nm}\right.$, average) respectively for the variant $\mathrm{SP}-\mathrm{B}_{1-25}$ and wild-type SP-C. The root mean square deviation (RMSD) after least square fit to backbone were found to be within the acceptable range. The average values were
$0.021,0.020,0.026$ and $0.035 \mathrm{~nm}$ for wild-type SP-B, variant $\mathrm{SP}-\mathrm{B}_{1-25}$, wild-type SP-C and variant $\mathrm{SP}_{-} \mathrm{C}_{f f}$, respectively (Fig. 1). Furthermore, the characteristics obtained from best PPI study (Table S1, supplementary section) reveal a possible mode of action of the LS proteins and their peptide mimics. In addition, the docking topology and atomic contact energy (ACE) of the LS proteins and their peptide mimics suggest a clear contact with membrane surface proteins (Fig. 3). However, the characteristics obtained from Firedock algorithm suggest that the wild-type SP-B have little expensive interaction with bam A and $l p t \mathrm{D}$ but the ClasPro balanced weighted energy scores indicate a favorable interaction with different binding topology (Figs. 4 and S1). Moreover, the PPI between variant SP-C $\mathrm{C}_{f f}$ with bamA suggests an excellent binding interaction (Table S1) inside the loop 1 of the bamA (Fig. 4). 

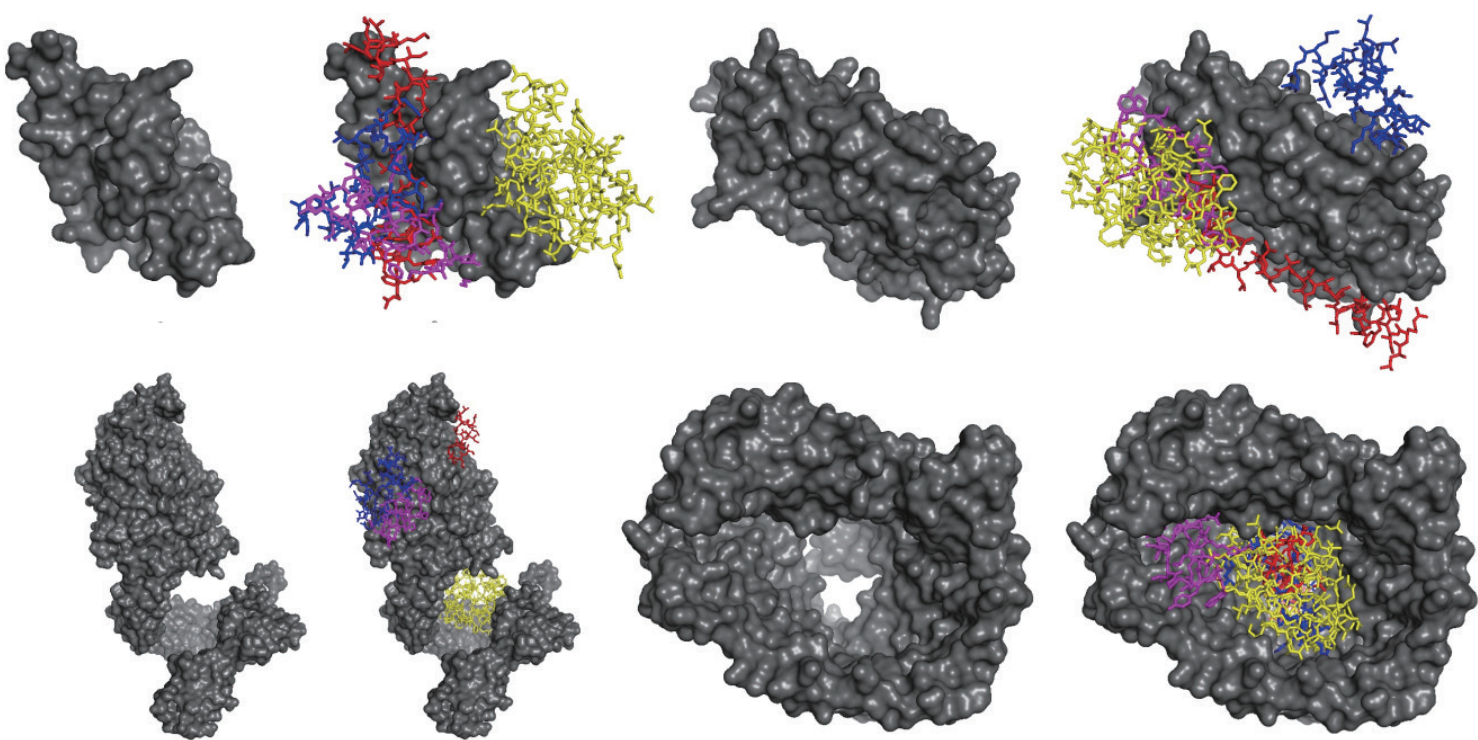

Fig. 3 Docking topology of cell surface proteins with LS proteins and their peptide mimics. (A), isdA; (B), isdC; (C),

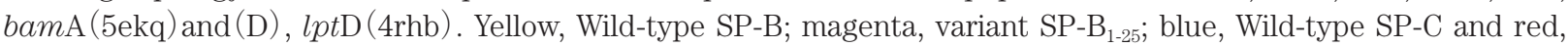
variant $\mathrm{SP}-\mathrm{C}_{f f}$.

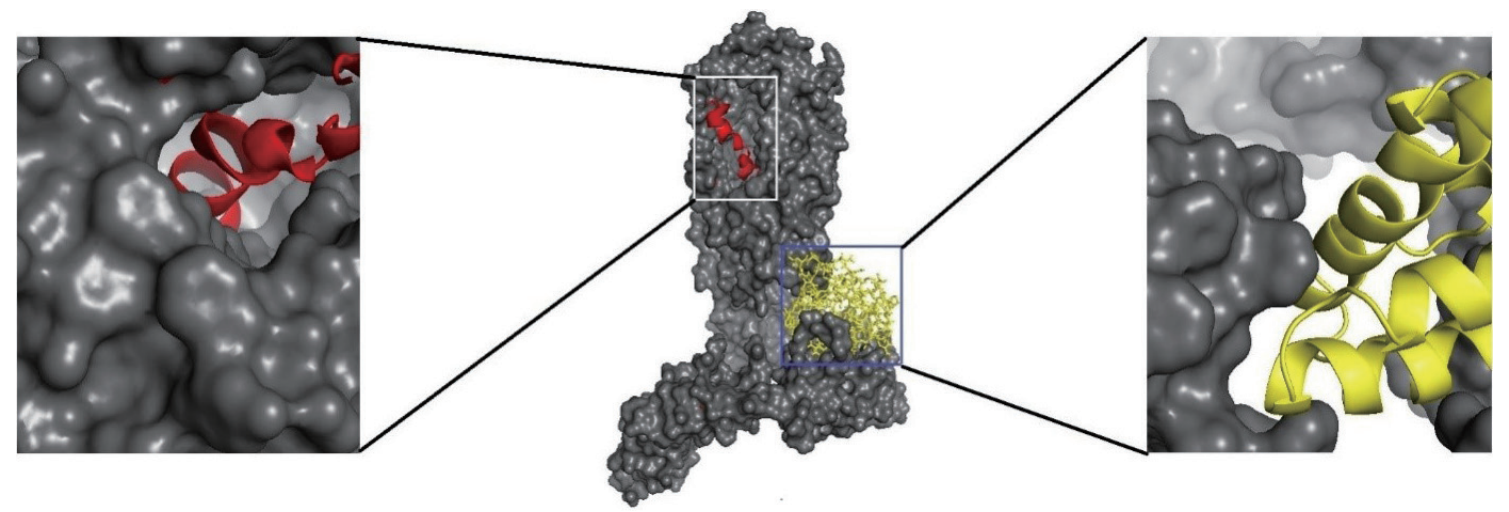

Fig. 4 Docking topology of Variant SP-C $\mathrm{C}_{f f}$ and wild-type SP-B with $\beta$-barrel OM protein bamA. (A), best Firedock topology of the variant $\mathrm{SP}_{-\mathrm{C}_{f f}}$ inside the loop 1 of the $\beta$-barrel $\mathrm{OM}$ protein bamA; $(\mathrm{B})$, bamA with variant $\mathrm{SP}-\mathrm{C}_{f f}$ and Wild-type $\mathrm{SP}-\mathrm{B}$; (C), ClasPro balanced weighted topology of the wild-type SP-B with bamA. Red, variant $\mathrm{SP}-\mathrm{C}_{f f}$ and yellow, Wild-type SP-B.

\subsection{Transmission/Scanning Electron Microscopy (TEM) and Atomic Force Microscopic (AFM) Studies}

Scanning electron micrographs of $E$. coli in the absence (panels A and C) and presence (panels B and D) of BLES at $2.0 \mathrm{mg} / \mathrm{mL}$ are shown in Fig. 5. The preparations of $S$. aureus with and without BLES at $7 \mathrm{mg} / \mathrm{mL}$ are shown in panels E and F of Fig. 5, respectively. At low magnifications, no distinct differences in the bacterial dispersions were noticed (B), other than the smaller number of the bacteria present and remnants of BLES vesicular dispersions, seen in the sample. At higher magnification $(\mathrm{C}$ and D), however, in some cases large batches of $E$. coli were found to show intact double membranes and a clear cytoplasm (C) without surfactant, compared to those with BLES (D). In case of those with BLES, the double membranes were found to be more smeared as well as the bacterial interior were found to be well stained. As osmium tetraoxide is a stain for lipids, it can be safely presumed from these images that the lipid rich BLES was somehow being incorporated in the cytoplasm of the bacteria. Figure 6 describes the combined TEM (panels A, B) and AFM (panels C, D) images for $S$. auerus. The single membrane for the species was clearly visible for samples with TSB alone (panel A) and BLES treated (panel B) provide the evidence for disrupted cell membrane which resulted in the leaky bio-membranes, leading to eventual death of the cell. In addition, the reduced number of the single membrane for the species also depicted from the TEM study. However, in the presence of BLES almost in all samples examined, the membranes were found to be ruptured (arrow marks in Fig. 

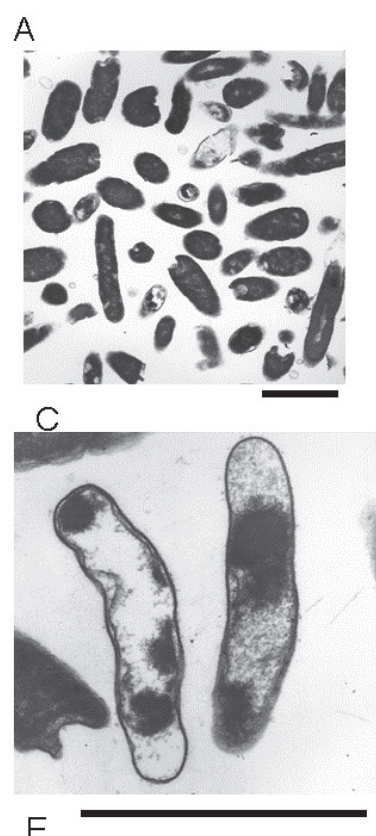

E

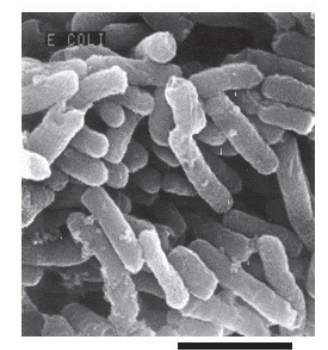

B

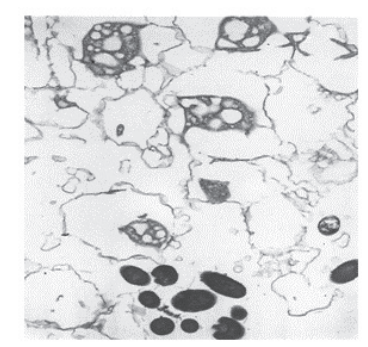

D
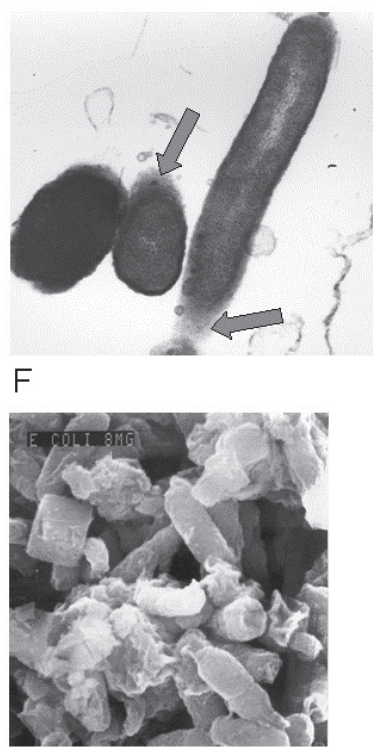

Fig. 5 Transmission electron microscopy(TEM) and scanning electron microscopic (SEM)images of BLES $^{\mathrm{TM}}$ untreated (left panels) and treated (right panels)E. coli cells. Magnification: A, $3000 \mathrm{x}$; B, $3000 \mathrm{x}$; C, $9000 \mathrm{x}$ and D, $9000 \mathrm{x}$. The arrow points towards the obvious changes in the morphology of the cell envelope. SEM images of $E$. coli cells untreated $(\mathrm{E})$ and treated $(\mathrm{F})$ with $\mathrm{BLES}^{\mathrm{TM}}$ (bottom panels). The micrograph in $\mathrm{F}$ suggests that clumping of cells occurred.

6D). Smoothness of the intact cell surface was suggested by the AFM study (Fig. 6C). Results suggest that BLES could significantly affect the outer single bilayer membranes of $S$. aureus, more profoundly than E. coli. Smearing of the $E$. coli membranes are also indicative of surfactant interactions with this bacterial species.

\subsection{Effects of DPPC and DPPC/POPG on the growth of Staphylococcus aureus}

Figure 7 shows the growth of $S$. aureus in different concentrations of DPPC/POPG (A) and hydrophobic LS mimetic peptides incorporated in model liposome (B and C) which were also present in the BLES ${ }^{\mathrm{TM}}$ experiments. No significant decrease in the bacterial growth was apparent
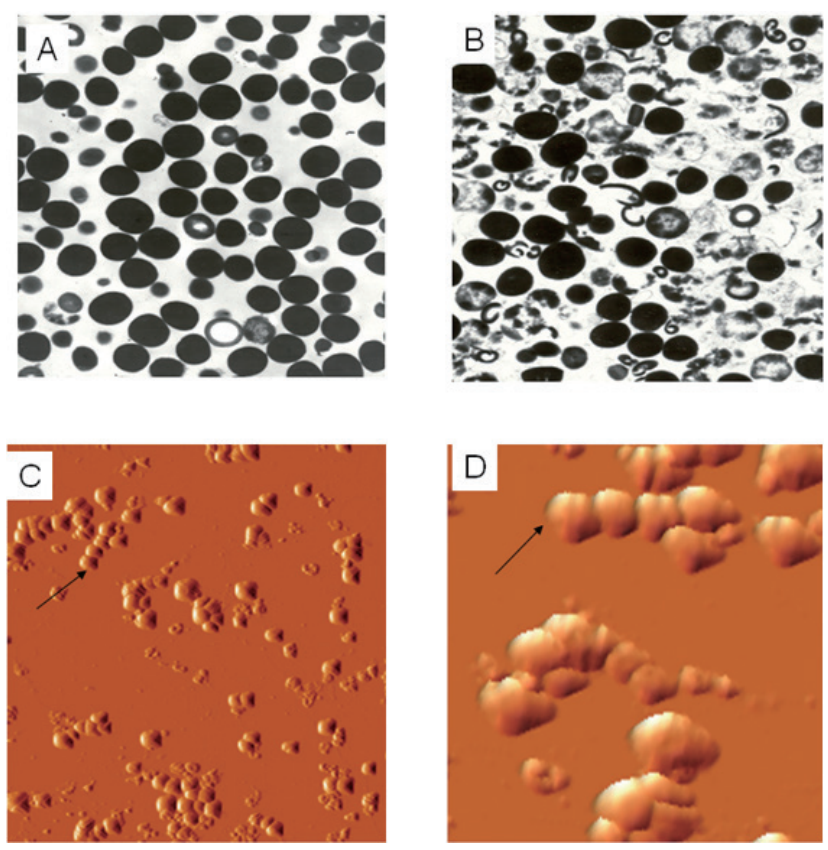

Fig. 6 Transmission Electron Microscopy(TEM) of BLES $^{\text {TM }}$ untreated (A) and treated (B) S. aureus cells. Atomic force microscopic (AFM) images of $S$. aureus cells ( $\mathrm{C}$ and $\mathrm{D})$. The arrow in $\mathrm{D}$ indicates changes in the morphology of the cell envelope.

compared to the growth without DPPC (data not shown). Incubation of $S$. aureus in DPPC/POPG resulted in a mild increase of growth compared to the growth without these lipids. It could, therefore, be concluded that the lipids are not the components in BLES ${ }^{\mathrm{TM}}$ which are responsible for the inhibitory effect on the growth of $S$. aureus.

\subsection{Effects of SP-B and SP-C on the growth of Escherich- ia coli}

Incubation of $E$. coli in DPPC/POPG with 8 wt\% SP-B demonstrated decreased viability of the bacteria compared to the incubation in TSB alone. Results, as graphically shown in Fig. 8, suggest that there occurred significant decrease in the growth of the bacterial colony in presence of the synthetic peptides. In the presence of $\mathrm{DPPC} / \mathrm{POPG}$ with 8 wt \% SP-C the growth of $E$. coli resulted in a similar growth pattern. A remarkable decrease is apparent over the whole used concentration range(Fig. 8B) .

\section{Discussion}

The major objective of this study was to examine the effect of lung surfactant on the proliferation of gram-negative and gram-positive bacteria, where the specific components of surfactant involved in inhibitions of the species were explored in vitro and in silico. The results depicted by the in vitro study are also in agreement with PPI study 

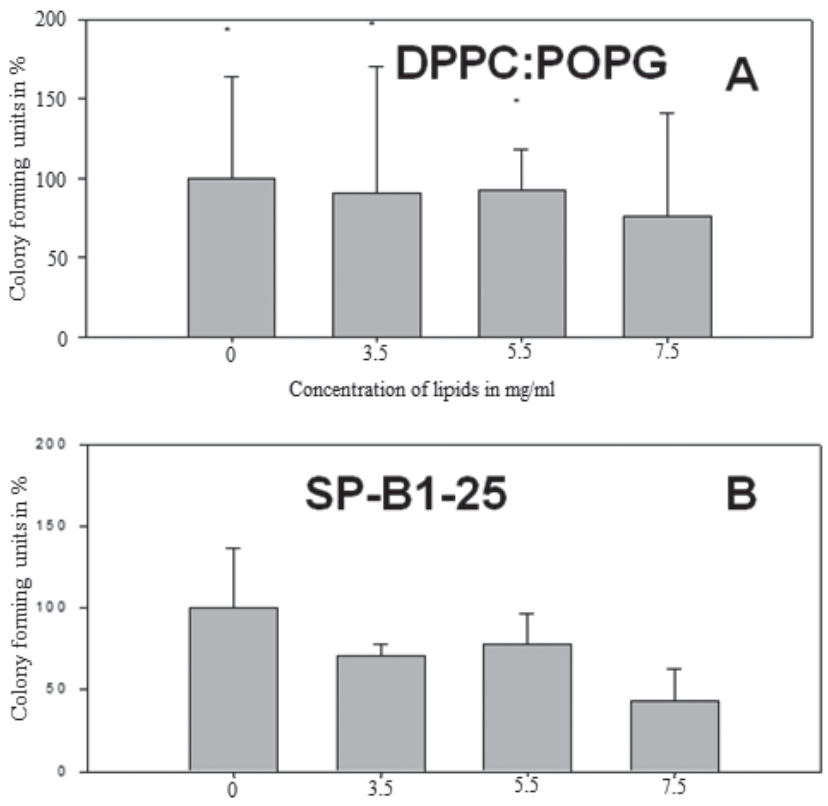

Concentration of SP-B ${ }_{1-22}$ peptide in $\mathrm{mg} / \mathrm{ml}$

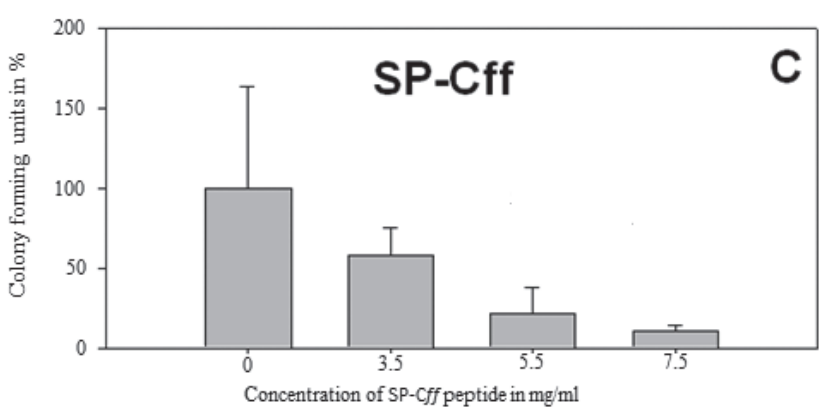

Fig. 7 Antimicrobial effect of artificial LS models (DPPC $+\mathrm{POPG})$ in the absence and presence of indicated amount of the synthetic variants on the growth pattern of $S$. aureus. (A), LS model(DPPC + POPG) only; (B), SP-B-25 along with DPPC + POPG and $(\mathrm{C}), \mathrm{SP}_{-} \mathrm{C}_{f f}$ along with DPPC + POPG. The lipids DPPC and POPG were mixed and combined with the peptides.

(Table S1, supplementary section). The emergence of multidrug resistance superbugs and subsequent failure of conventional antimicrobial therapy spontaneously promotes the hunch of alternatives. The outer membrane $(\mathrm{OM})$ proteins have recently gained potential interest as the next-generation drug targets ${ }^{53)}$. Therefore, we also look through such way to predict the possible mechanism of action of the LS peptides and their peptides mimics. In the previous study, it has been reported that is $\mathrm{A}$, a cell surface receptor protein indulge in iron acquisition, confers resistance to bactericidal activity and antibodies active specifically against isdA enhanced killing of $S$. aureus ${ }^{25)}$. This surface receptor gene cluster acts by employing is $\mathrm{H}$, $i s d \mathrm{~B}$, isd $\mathrm{A}$ expressed outside of the rigid cell wall followed by $i s d \mathrm{C}$, is $d \mathrm{E}$ and $i s d \mathrm{~F}$ attached to the cell membrane and $i s d \mathrm{~A}$ and $i s d \mathrm{C}$ are juxtaposed. As indicated by PPI study SP-B/-C and their peptide mimics pose strong binding affinity with $i s d \mathrm{~A}$ and $i s d \mathrm{C}$ (Fig. 3 and Table S1). Therefore, we speculate that disruption of the outer surface by the LS peptides and their mimics eventually occurs by inhibiting $i s d \mathrm{~A}$ and $i s d \mathrm{C}$ which further enhanced the killing of the bacteria. Likewise, in $E$. coli the $\beta$-barrel OM proteins bam $\mathrm{A}$ and $l p t \mathrm{D}$ have previously been reported to be involved in the peptide(JB-95) induced OM stress response leading to lethal disruption of the OM through direct inhibition of Bam folding ${ }^{24)}$. The results obtained from PPI study (Fig. 4) demonstrate that Wild-type SP-B and Variant SP-C Cff $_{f f}$ bind (loop1) to bamA with a strong binding affinity (Table S1). More to the point, wild type and peptide mimics of the SP-B/-C bind with the inner core of the $\beta$-barrel OM proteins $l p t \mathrm{D}$ (Fig. 3). Therefore, we also speculate that it may trigger OM stress resulting lethal disruption of the OM. The emergence of multi-drug resistant superbugs and subsequent failure of the conventional antimicrobial drug is mostly related to the surface properties of the cell ${ }^{54}$. The SEM. TEM, AFM (Figs. 5 and 6) combined study support the possible intrusion of the hydrophobic LS peptide and their mimics by disabling selective permeability of the cell. Moreover, the ambiguous PPI study confers a possible interaction of the LS peptides and their mimics with cell surface protein molecules essential for bacterial survival. Thus, combining the microscopic and PPI study it may be concluded that the hydrophobic LS-peptides and their mimetic copies have bacterial activities. In addition to the PPI study, the MD simulation depicts minimal fluctuation of gyration radius in total and around the axis (Fig. 2) of the LS proteins and their mimics indicating they have quite a stable backbone at them. The backbone stability is a prerequisite for novel antibacterial peptide for therapeutic use ${ }^{26)}$. It further validates the PPI and their characteristic suggesting LS proteins and their peptide mimics could be used in future therapeutics. Results clearly suggest that the hydrophobic surfactant proteins exhibit substantial anti-microbial activities up to certain level. For both E. coli and $S$. aureus, decrease in the growth or proliferation of bacterial cells to a modest value of 50\% was observed with BLES in comparison to the systems without the surfactant. According to the previous reports, lung lavage consisting the lectins SP-A and SP-D can cause sub-lethal damage of E. $\operatorname{coli}^{55)}$. A recent work was suggested pro-inflammatory and anti-inflammatory roles for SP-A/-D that is supposed to be involved in potential damage by pathogens and allergens ${ }^{20)}$. However, a prior study suggests SP-B/-C confer relatively low immunity compared to SP-A/- ${ }^{56}$. Bacterial cells became susceptible to death by anionic detergent in the presence of lung lavage. At least $70 \%$ reduction of the microbial counts on deoxycholate agar was reported ${ }^{57)}$. However, for Survanta, a natural modified surfactant 

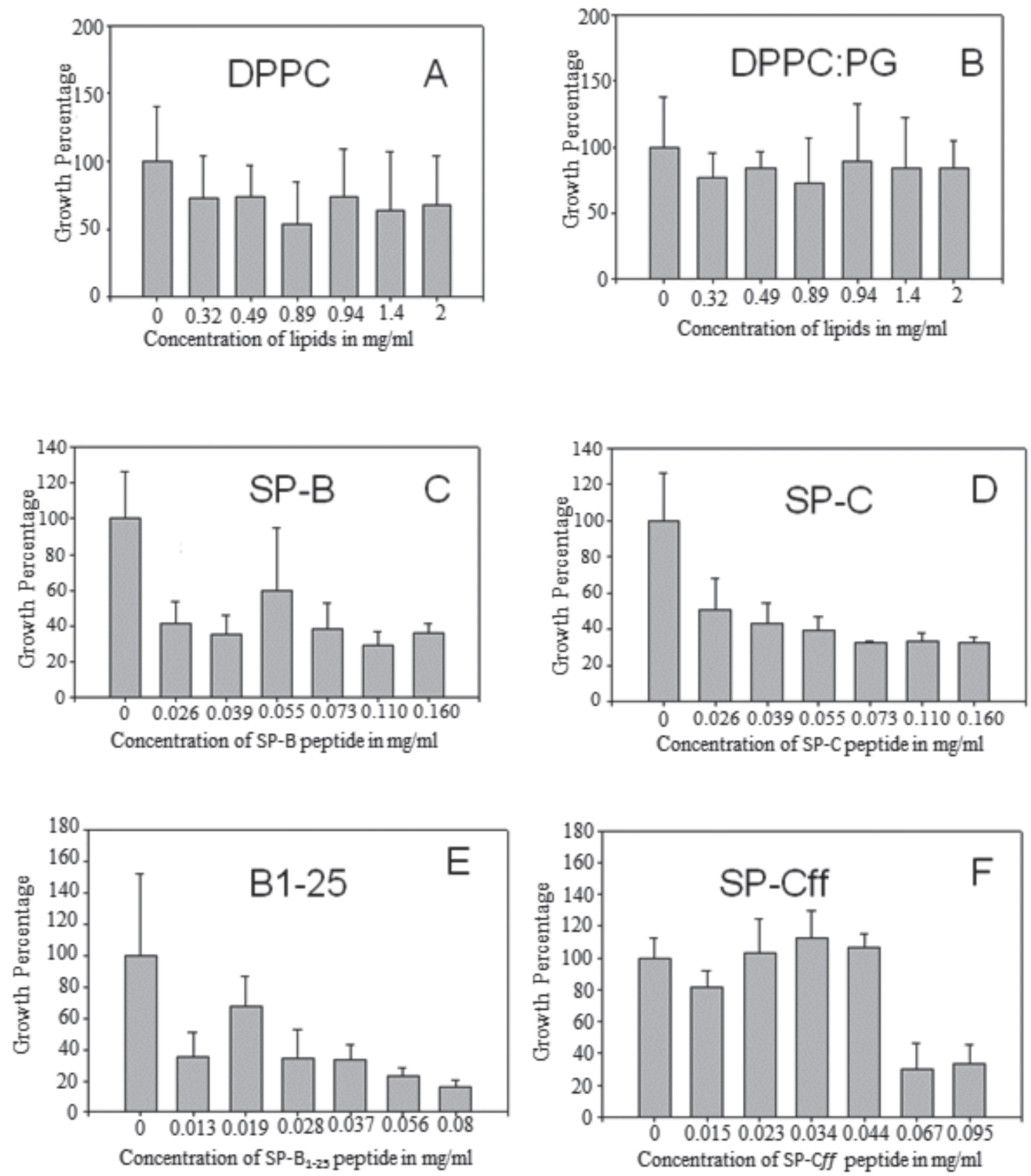

Fig. 8 The antimicrobial effect of artificial LS models (DPPC + POPG) in the absence and presence of indicated amounts of the LS peptides on growth pattern of E. coli. (A), DPPC; (B) DPPC + POPG; (C), SP-B with DPPC + POPG; (D), SP-C with DPPC + POPG; (E), SP-B $1_{1-25}$ with DPPC + POPG; and (F), SP-C $\mathrm{C}_{f f}$ with DPPC + POPG. The lipids DPPC and POPG were mixed and combined with the peptides.

similar or close to the composition of BLES, can actually accelerate the growth of $E$. coli ${ }^{48,58)}$. Although in these studies various clinical preparations and concentrations were used against an arsenal of bacterial species, these studies have however suggested that surfactant preparations with the hydrophobic proteins (Survanta) tend to perform better than those without the proteins (Exosurf) in inhibiting proliferation of certain species of bacteria $^{34)}$. $S$. aureus can use the lipids as nutrients, because it is capable of producing enzymes such as phospholipase that can degrade lipids and make them accessible as nutrients $^{59)}$. Because the lipids are not responsible for the inhibitory effect of BLES ${ }^{\mathrm{TM}}$, effects of the surfactant protein B and $\mathrm{C}$ on the in vitro growth of $E$. coli were also investigated. Both the proteins exhibited distinct inhibitory effects on the proliferation of $E$. coli (Fig. 8). SP-B is a di- 
sulphide-linked homodimer comprising two polypeptide chains with 79 residues each. It is a cationic protein and the native SP-B protein has a net charge of 8 (10 cationic and 2 anionic residues), a large fraction of strongly hydrophobic residues, and four amphipathic helical segments with the helical axes oriented parallel to the interface ${ }^{60}$. The SP-B monomer contains seven cysteine residues, of which six form intramolecular disulphide bonds. Cysteine seven forms an intermolecular disulphide bridge, which is responsible for the dimerization of two SP-B monomers ${ }^{19)}$. SP-B belongs to the amoebapore superfamily. Most of the proteins that comprise this superfamily contain six conserved cysteine residues, which can form three disulphide bridges. Structurally, they belong to the family of saposin like proteins (SAPLIPS), and a common property of these proteins is their ability to interact with lipids. They also have common functional features to possess antibacterial activities. Primarily they are capable of permeating through the membranes (pore formation) after binding to phospholipids, and hence their activities do not depend on the interaction with a specific receptor ${ }^{61)}$. Antibacterial activity and cytotoxicity to tumor cells have been reported for NKlysine and other amoebapores ${ }^{11)}$. They can generate pores in the outer membrane (OM) of gram-negative bacterial cells; subsequently they can pass through the OM in reaching to the inner membrane. This is the plausible mechanism for killing the gram-negative bacteria, because the formation of pores in the $\mathrm{OM}$ is not primary criterion to kill the bacteria $^{62)}$. Structural similarity between SP-B and the positive charge of this molecule suggest that it can act in the same way as antimicrobial agent. It is known that SP-B induces the immune response via the airways. When SP-B containing antigen vesicles were instilled in the trachea of mice, a systemic immune response was induced ${ }^{17}$. Elevated levels of SP-B in the airspaces of transgenic mice were associated with decreased inflammation following exposure to endotoxins. Therefore, it could be proposed that SP-B is an important factor in the defence of infections in the lung, because it is known that SP-B deficiency is present after infections with bacteria and viruses, or treatment of mice with endotoxins ${ }^{63)}$. Incubation of $E$. coli with SP-C also shows a significant decrease of the growth compared to the growth without SP-C (Fig. 8D). SP-C is more hydrophobic than SP-B as it contains more than 70\% non-polar residues and carries covalently linked fatty acyl chains. It is a 35residue peptide chain with two thioester-linked palmitoyl groups. Primary structure of SP-C is evolutionarily conserved and it appears to be the only constituent, unique to pulmonary surfactant. SP-C has a regular $\alpha$-helical structure which is amphiphilic, where the Lys-Arg pair at positions 11 and 12 present positive charges and polar side chains and the poly-valyl helix exposes an extended and nearly uniform lipophilic surface ${ }^{19)}$. SP-C is able to bind to lipopolysaccharide(LPS), one of the major components of the outer membrane of gram-negative bacteria ${ }^{64)}$. It binds to the lipid A part of the LPS, which is the hydrophobic anchor of the whole LPS molecule. Chemically, lipid A is a glucosamine-based phospholipid which is glycosylated with a non-repeating oligosaccharide, designated the core. The eight-carbon sugar, 3-deoxy-D-manno-oct-2-ulosonic acid (KDO) is linked directly to lipid A. The lipid A with the $\mathrm{KDO}$ disaccharide is essential for the growth of E. coli. Both, the lipid A and the KDO disaccharide, bear negative charges. The lipid character and the anionic charges of lipid A make it a potential target for cationic and hydrophobic drugs such as polymyxi ${ }^{65}$. Thus it is not unexpected that there would be strong interaction between the LPS and SP-C. The mechanism by which SP-C acts on the outer membrane is not clear, but as it is able to bind to the LPS, it could destroy the ordered structure of the outer leaflet of the outer membrane. The outer leaflet is stabilized by divalent cations such as $\mathrm{Mg}^{2+}$ and $\mathrm{Ca}^{2+}$. Removal of the divalent cations by other cationic molecules induce the release of the LPS from the bacterial surface and render the cells permeable to hydrophobic organic compounds ${ }^{65)}$. As a result, SP-C can enter into the bacterial cell and can reach the inner membrane and exert antimicrobial activity. Another action of SP-C in the host defence has been established recently. As SP-C interact with the LPS and CD14 receptor, the cell surface binding site of the LPS, it can function as shuttle for the LPS to these receptors on the alveolar cells. CD14 and LPS can interact with the same region of the SP-C molecule, hence SP-C enhances the binding of CD14 to LPS. CD14 is a pattern recognition molecule which plays a central role in inflammation. The interaction of SP-C and CD14 indicates the immunological role of SP-C during microbe induced lung inflammation processes $^{66)}$. The synthetic analogs of SP-B and SP-C, SP-B $1-25$ and $\mathrm{SP}_{-} \mathrm{C}_{f f}$, used in this study, have also shown inhibitory effects on the growth of $E$. coli. The observed inhibitory effect of SP-B $\mathrm{B}_{1-25}$ was stronger than the native SP-B protein. SP-B $\mathrm{B}_{1-25}$ peptide (Fig. 8) exhibited greater inhibition than the native SP-B (Fig. 8) even at a 50\% reduction in concentration. The $\mathrm{SP}_{-} \mathrm{C}_{f f}$ peptide was not as potent as $\mathrm{SP}-\mathrm{B}_{1-25}$; only at higher concentrations of SP- $\mathrm{C}_{f f}$ inhibited the proliferation of $E$. coli (Fig. 8). Both the peptides possess cationic charge and amphipathic features. SP- $\mathrm{B}_{1-25}$ is a synthetic peptide based on the N-terminus of the native SP-B protein. It's amphipathic helices (similar to the native SP-B) that helps to orient the molecule at the interface and bears a net positive charge of 4 . SP- $\mathrm{C}_{f f}$ peptide is the analog of the native SP-C protein, in which the palmitoylated cysteines are replaced by phenylalanine residues and bears a net positive charge of $3^{60)}$.

During the last few years, lot of antimicrobial peptides could be identified that belong to the innate host defence molecules of several organisms, like protegrin-1 (PG-) present in procine leukocytes ${ }^{67)}$ magainin from the skin of 
the frog Xenopus laevis ${ }^{68)}$ cecropins which are present in insect hemolymph and the pig intestines ${ }^{69)}$ SMAP-29 found in sheep leukocytes ${ }^{70)}$, various types of defensins found in mammals, insects and plants ${ }^{71)}$, and many more ${ }^{72)}$. All these antimicrobial peptides have common features, viz., they are cationic and amphipathic molecules with 16-40 residues, but a few smaller peptides with 11-13 residues have also been described ${ }^{73)}$. Some of these molecules, like defensins and protegrins, contain disulfide bonds also, such as $\mathrm{SP}-\mathrm{B}^{74)}$. They all act in the same way on the membranes of a wide range of bacteria to exert their antimicrobial actions. Bacterial membranes abundantly contain negatively charged lipids such as phosphatidylglycerol, cardiolipin and lipopolysaccharide (LPS) which enhance the membrane binding efficiency of these peptides. The peptides can form pores and in some cases they increase the permeability of the bacterial inner and outer membranes. The initial interactions of some cationic peptides with gram-negative bacteria involve binding to surface LPS. The peptides can displace the divalent cations, essential for outer membrane integrity. Consequently, they can distort the outer membrane bilayer ${ }^{75)}$. In case of gram-positive bacteria, the peptides interact with the cytoplasmic membrane and disrupt their structure. This can dissolve the proton motive force and the leakage of essential molecules, eventually leading to cell death ${ }^{76)}$.

Synthetic peptides used in the study, SP-B $\mathrm{B}_{1-25}$ and $\mathrm{SP}_{\mathrm{C}}$, have the common features of the aforementioned antimicrobial peptides such as the positive charge and amphipathic nature. Therefore, it is possible that they would interact in the same way with the bacterial membrane like the antimicrobial peptides. Comparison of membrane interactions of model peptides has shown that electrostatic interactions with anionic lipids that dominate over the peptide secondary structure in interactions with bacterial membranes. Only when the model peptides possess the same charge, strength of the interaction depends on its secondary structure ${ }^{77)}$. This could be the reason for the observed lower potency of $\mathrm{SP}_{-} \mathrm{C}_{f f}$ peptide to inhibit the growth of $E$. coli. Compared to the $\mathrm{SP}_{-} \mathrm{B}_{1-25}$ peptide, $\mathrm{SP}_{-} \mathrm{C}_{f f}$ peptide possesses one less positive charge. Studies have shown that the hydrophobic pulmonary proteins SP-B and SP-C exhibit antimicrobial activity and are able to inhibit the growth of $E$. coli in vitro. The synthetic protein analogs have the same impact that makes it possible to develop new antimicrobial drugs to treat infections in the lung. Several studies with synthetic analogs of SP-B and SP-C have established that they are also able to mimic the biophysical properties of the native proteins ${ }^{19)}$. Therefore, the synthetic peptides could potentially substitute the function of native SP-B and SP-C in synthetic surfactant preparations.

\section{Conclusion}

In the pursuit of having potential antimicrobial drug candidate, antimicrobial peptides (AMPs) have now become interesting to the scientific community. The cationic charge, amino acid composition, low propensity and favourable three dimensional structure of the AMPs allow them easily to attach to the membrane bilayer leading lethal disruption of the membrane. Overall, the physico-chemical properties of AMPs make them good drug candidates. This study enlightens the effects of SP-B/-C, SP-B ${ }_{1-25}$ and $\mathrm{SP}-\mathrm{C}_{f f}$ on bacterial in vitro growth kinetics. In addition, the microscopic study at nano-resolution and in vitro growth kinetic study combined suggest a paradoxical bactericidal effect of the hydrophobic LS-protein and peptides. More to the point, the in silico approach using ambiguous peptide docking algorithms propose a possible mode of action through disruption of membrane surface proteins, essential for bacterial survival. However, further study is needed to understand the exact bactericidal mode of action of the hydrophobic L6S-proteins and peptides.

\section{Acknowledgments}

The work is supported by the Department of Biotechnology, Govt. of India (Project Number: BT/PR3802/ BRB/10/981/2011). K. D. acknowledges the Department of Science and Technology, Govt. of India(DST Ref. No. INT/ RUS/RFBR/P-220) for a fellowship. Authors sincerely thank Lisa Lee for generously performing the TEM analyses.

\section{Conflict of Interest}

Authors declare no conflict of interest

\section{Supporting Information}

This material is available free of charge via the Internet at http://dx.doi.org/jos.67.10.5650/jos.ess.18026

\section{References}

1) Whitsett, J.A.; Hull, W.M.; Luse, S. Failure to detect surfactant protein-specific antibodies in sera of premature infants treated with survanta, a modified bovine surfactant. Pediatrics 87, 505-510 (1991).

2) Glasser, S.W.; Witt, T.L.; Senft, A.P.; Baatz, J.E.; Folger, D. et al. Surfactant protein C-deficient mice are susceptible to respiratory syncytial virus infection. Am. J. Physiol. 297, L64-L72 (2009).

3) Glasser, S.W.; Maxfield, M.D.; Ruetschilling, T.L.; Akin- 


\section{Bactericidal Effect of Lung Surfactant Proteins}

bi, H.T.; Baatz, J.E. et al. Persistence of LPS-induced lung inflammation in surfactant Protein-C-deficient mice. Am. J. Resp. Cell Mol. Biol. 49, 845-854(2013).

4) Haagsman, H.P.; Diemel, R.V. Surfactant-associated proteins: functions and structural variation. Comp. Biochem. Physiol. A: Physiol. 129, 91-108(2001).

5) Vaccaro, A.M.; Salvioli, R.; Tatti, M.; Ciaffoni, F. Saposins and their interaction with lipids. Neurochem. Res. 24, 307-314(1999).

6) Whitsett, J.A.; Weaver, T.E. Hydrophobic surfactant proteins in lung function and disease. New England $J$. Med. 347, 2141-2148(2002).

7) Ernst, C.M.; Peschel, A. Broad-spectrum antimicrobial peptide resistance by MprF-mediated aminoacylation and flipping of phospholipids. Mol. Microbiol. 80, 290299 (2011).

8) Baoukina, S.; Tieleman, D.P. Direct Simulation of Protein-Mediated Vesicle Fusion: Lung Surfactant Protein B. Biophys. J. 99, 2134-2142(2010).

9) Klein, J.M.; McCarthy, T.A.; Dagle, J.M.; Snyder, J.M. Antisense inhibition of surfactant protein A decreases tubular myelin formation in human fetal lung in vitro. Am. J. Physiol. 282, L386-L393 (2002).

10) Banaschewski, B.J.; Veldhuizen, E.J.; Keating, E.; Haagsman, H.P.; Zuo, Y.Y. et al. Antimicrobial and biophysical properties of surfactant supplemented with an antimicrobial peptide for treatment of bacterial pneumonia. Antimicrob. Agents Chemother. 59, 3075-3083 (2015).

11) Johansson, J. Structure and properties of surfactant protein C. Biochim. Biophys. Acta 1408, 161-172 (1998).

12) Ballard-Croft, C.; Wang, D.; Sumpter, L.R.;Zhou, X.; Zwischenberger, J.B. Large-animal models of acute respiratory distress syndrome. Ann. Thorac. Surg. 93, 1331-1339 (2012).

13) Wilder, M.A. Surfactant protein B deficiency in infants with respiratory failure. J. Perinat. Neonat. Nursing. 18, 61-67(2004).

14) Herting, E.; Gefeller, O.; Land, M.; Van Sonderen, L.; Harms, K. et al. Surfactant treatment of neonates with respiratory failure and group B streptococcal infection. Pediatrics 106, 957-964(2000).

15) McCormack, F.X.; Whitsett, J.A. The pulmonary collectins, SP-A and SP-D, orchestrate innate immunity in the lung. J. Clin. Invest. 109, 707 (2002).

16) Holm, B.A.; Matalon, S. Role of pulmonary surfactant in the development and treatment of adult respiratory distress syndrome. Anesth. Analg. 69, 805-818(1989).

17) Augusto, L.; Le Blay, K.; Auger, G.; Blanot, D.; Chaby, R. Interaction of bacterial lipopolysaccharide with mouse surfactant protein $\mathrm{C}$ inserted into lipid vesicles. Am. J. Physiol. 281, L776-L785(2001).

18) Parra, E.; Alcaraz, A.; Cruz, A.; Aguilella, V.M.; Pérez-
Gil, J. Hydrophobic pulmonary surfactant proteins SP-B and SP-C induce pore formation in planar lipid membranes: evidence for proteolipid pores. Biophys. J. 104, 146-155 (2013).

19) Zhai, Y.; Saier, M.H. The amoebapore superfamily. Biochim. Biophys. Acta 1469, 87-99(2000).

20) Krafft, M.P. Overcoming inactivation of the lung surfactant by serum proteins: a potential role for fluorocarbons? Soft Matter 11, 5982-5994(2015).

21) Wemhöner, A.; Jennings, P.; Haller, T.; Rüdiger, M.; Simbruner, G. Effect of exogenous surfactants on viability and DNA synthesis in A549, immortalized mouse type II and isolated rat alveolar type II cells. BMC Pulm. Med. 11, 11 (2011).

22) Herting, E.; Sun, B.; Jarstrand, C.; Curstedt, T.; Robertson, B. Surfactant improves lung function and mitigates bacterial growth in immature ventilated rabbits with experimentally induced neonatal group B streptococcal pneumonia. Arch. Dis. Childhood-Fetal Neonat. Ed. 76, F3-F8(1997).

23) Ryan, M.A.; Akinbi, H.T.; Serrano, A.G.; Perez-Gil, J.; $\mathrm{Wu}, \mathrm{H}$. et al. Antimicrobial activity of native and synthetic surfactant protein B peptides. J. Immunol. 176, 416-425 (2006).

24) Urfer, M.; Bogdanovic, J.; Monte, F.L.; Moehle, K.; Zerbe, K. et al. A peptidomimetic antibiotic targets outer membrane proteins and disrupts selectively the outer membrane in Escherichia coli. J. Biol. Chem. 291, 1921-1932(2016).

25) Clarke, S.R.; Foster, S.J. IsdA protects Staphylococcus aureus against the bactericidal protease activity of apolactoferrin. Infect. Immun. 76, 1518-1526 (2008).

26) Comune, M.; Rai, A.; Chereddy, K.K.; Pinto, S.; Aday, S. et al. Antimicrobial peptide-gold nanoscale therapeutic formulation with high skin regenerative potential. $J$. Cont. Rel. 262, 58-71 (2017).

27) Berger, J.; Diab-Elschahawi, M.; Blacky, A.; Pernicka, E.; Spertini, V. et al. A matched prospective cohort study on Staphylococcus aureus and Escherichia coli bloodstream infections: extended perspectives beyond resistance. Am. J. Infect. Cont. 38, 839-845 (2010).

28) Farver, R.S.; Mills, F.D.; Antharam, V.C.; Chebukati, J.N.; Fanucci, G.E. et al. Lipid polymorphism induced by surfactant peptide SP-B 1-25. Biophys. J. 99, 1773-1782(2010).

29) Eagle, H.; Musselman, A. The rate of bactericidal action of penicillin in vitro as a function of its concentration, and its paradoxically reduced activity at high concentrations against certain organisms. J. Exp. Med. 88, 99-131 (1948).

30) Grünenfelder, B.; Rummel, G.; Vohradsky, J.; Röder, D.; Langen, H. et al. Proteomic analysis of the bacterial 
K. Dutta, K. Nag, V. Booth et al.

cell cycle. Proc. Nat. Acad. Sci. USA 98, 4681-4686 (2001).

31) Shah, P.M. Paradoxical effect of antibiotics: I. The 'Eagle effect'. J. Antimicrob.Chemother. 10, 259-260 (1982).

32) Wang, Y.; Griffiths, W.J.; Curstedt, T.; Johansson, J. Porcine pulmonary surfactant preparations contain the antibacterial peptide prophenin and a C-terminal 18-residue fragment thereof. FEBS Lett. 460, 257-262 (1999).

33) Neumeister, B.; Woerndle, S.; Bartmann, P. Effects of different surfactant preparations on bacterial growth in vitro. Neonat. 70, 128-134(1996).

34） Rauprich, P.; Möller, O.; Walter, G.; Herting, E.; Robertson, B. Influence of modified natural or synthetic surfactant preparations on growth of bacteria causing infections in the neonatal period. Clin. Diag. Lab. Immun. 7, 817-822 (2000).

35) Miles, A.A.; Misra, S.; Irwin, J. The estimation of the bactericidal power of the blood. Epidem. Infect. 38, 732-749 (1938).

36) Webb, B.; Sali, A. Protein structure modeling with MODELLER. Protein Str. Pred. 1-15(2014).

37) Laskowski, R.; MacArthur, M.; Thornton, J. PROCHECK: validation of protein structure coordinates. in International tables of crystallography, Vol. F. Crystallography of Biological Macromolecules. Kluwer Academic Publishers, Netherlands, pp. 722-725 (2001).

38) Pronk, S.; Páll, S.; Schulz, R.; Larsson, P.; Bjelkmar, P. et al. GROMACS 4.5: a high-throughput and highly parallel open source molecular simulation toolkit. Bioinformatics 29, 845-854(2013).

39) Jorgensen, W.L.; Maxwell, D.S.; Tirado-Rives, J. Development and testing of the OPLS all-atom force field on conformational energetics and properties of organic liquids. J. Am. Chem. Soc. 118, 11225-11236 (1996).

40) Humphrey, W.; Dalke, A.; Schulten, K. VMD: visual molecular dynamics. J. Mol. Graph. 14, 33-38(1996).

41) Schneidman-Duhovny, D.; Inbar, Y.; Nussinov, R.; Wolfson, H.J. PatchDock and SymmDock: servers for rigid and symmetric docking. Nucleic Acids Res. 33, W363W367 (2005).

42) Mashiach, E.; Schneidman-Duhovny, D.; Andrusier, N.; Nussinov, R.; Wolfson, H.J. FireDock: a web server for fast interaction refinement in molecular docking. $\mathrm{Nu}$ cleic Acids Res. 36, W229-W232 (2008).

43) Kozakov, D.; Hall, D.R.; Xia, B.; Porter, K.A.; Padhorny, D. et al. The ClusPro web server for protein-protein docking. Nat. Protoc. 12, 255-278(2017).

44) DeLano, W.L.; Pymol: An open-source molecular graphics tool. CCP4 Newslett. Protein Crystall. 40, 82-92 (2002).

45) Brackenbury, A.M.; Puligandla, P.S.; McCAIG, L.A.;
Nikore, V.; Yao, L.J. et al. Evaluation of exogenous surfactant in HCL-induced lung injury. Am. J. Resp. Crit. Care Med. 163, 1135-1142 (2001).

46) Curstedt, T.; Johansson, J.; Persson, P.; Eklund, A.; Robertson, B. et al. Hydrophobic surfactant-associated polypeptides: SP-C is a lipopeptide with two palmitoylated cysteine residues, whereas SP-B lacks covalently linked fatty acyl groups. Proc. Nat. Acad. Sci. 87, 2985-2989 (1990).

47) Samad, A.; Sultana, Y.; Aqil, M. Liposomal drug delivery systems: an update review. Current Drug Deliv. 4, 297-305 (2007).

48) Nag, K.; Munro, J.G.; Hearn, S.A.; Rasmusson, J.; Petersen, N.O. et al. Correlated atomic force and transmission electron microscopy of nanotubular structures in pulmonary surfactant. J. Struct. Biol. 126, 1-15 (1999).

49) Sapkota, M.; Karmakar, G.; Nahak, P.; Guha, P.; Roy, B. et al. Effect of polymer charge on the formation and stability of anti-inflammatory drug loaded nanostructured lipid carriers: physicochemical approach. $R S C$ Adv. 5, 65697-65709 (2015).

50) Gad, M.; Ikai, A. Method for immobilizing microbial cells on gel surface for dynamic AFM studies. Biophys. J. 69, 2226-2233(1995).

51) Sakoulas, G.; Moise-Broder, P.A.; Schentag, J.; Forrest, A.; Moellering, R.C. et al. Relationship of MIC and bactericidal activity to efficacy of vancomycin for treatment of methicillin-resistant Staphylococcus aureus bacteremia. J. Clin. Microbiol. 42, 2398-2402 (2004).

52) Stichtenoth, G.; Jung, P.; Walter, G.; Johansson, J.; Robertson, B. et al. Polymyxin B/pulmonary surfactant mixtures have increased resistance to inactivation by meconium and reduce growth of gram-negative bacteria in vitro. Pediatric Res. 59, 407-411 (2006).

53) Davies, R.L. Outer membrane proteins as potential anti-infective drug targets in Mannheimia haemolytica. in Host-Pathogen Interaction: Microbial Metabolism, Pathogenicity and Antiinfectives. Wiley-VCH Verlag GmbH \& Co. KGaA, pp. 109-138(2016).

54) Gille, C.; Spring, B.; Bernhard, W.; Gebhard, C.; Basile, D. et al. Differential effect of surfactant and its saturated phosphatidylcholines on human blood macrophages. J. Lipid Res. 48, 307-317(2007).

55) Crouch, E.C.; Structure, biologic properties, and expression of surfactant protein D (SP-D). Biochim. Biophys. Acta 1408, 278-289 (1998).

56) Kishore, U.; Greenhough, T.J.; Waters, P.; Shrive, A.K.; Ghai, R. et al. Surfactant proteins SP-A and SP-D: structure, function and receptors. Mol. Immunol. 43, 1293-1315 (2006).

57) Grandière-Pérez, L.; Jacqueline, C.; Lemabecque, V.; Patey, O.; Potel, G. et al. Eagle effect in Corynebacterium diphtheriae. J. Infect. Dis. 191, 2118-2120 


\section{Bactericidal Effect of Lung Surfactant Proteins}

(2005).

58) Johansson, J.; Curstedt, T. Molecular structures and interactions of pulmonary surfactant components. FEBS J. 244, 675-693 (1997).

59) Hawgood, S.; Derrick, M.; Poulain, F. Structure and properties of surfactant protein B. Biochim. Biophys. Acta 1408, 150-160 (1998).

60) LaForce, F.M.; Boose, D.S. Sublethal damage of Escherichia coli by lung lavage 1-3. Am. Rev. Resp. Dis. 124, 733-737 (1981).

61) Epaud, R.; Ikegami, M.; Whitsett, J.A.; Jobe, A.H.; Weaver, T.E. et al. Surfactant protein B inhibits endotoxin-induced lung inflammation. Am. J. Resp. Cell Mol. Biol. 28, 373-378(2003).

62) Augusto, L.A.; Li, J.; Synguelakis, M.; Johansson, J.; Chaby, R. et al. Interaction of pulmonary surfactant protein $\mathrm{C}$ with CD14 and lipopolysaccharide. Infect. Immun. 71, 61-67(2003).

63) Raetz, C.R.; Whitfield, C. Lipopolysaccharide endotoxins. Ann. Rev. Biochem. 71, 635-700 (2002).

64) Augusto, L.A.; Li, J.; Synguelakis, M.; Johansson, J.; Chaby, R. et al. Structural basis for interactions between lung surfactant protein C and bacterial lipopolysaccharide. J. Biol. Chem. 277, 23484-23492 (2002).

65) Gidalevitz, D.; Ishitsuka, Y.; Muresan, A.S.; Konovalov, O.; Waring, A.J. et al. Interaction of antimicrobial peptide protegrin with biomembranes. Proc. Nat. Acad. Sci. 100, 6302-6307 (2003).

66) Matsuzaki, K.; Sugishita, K.I.; Harada, M.; Fujii, N.; Miyajima, K. Interactions of an antimicrobial peptide, magainin 2, with outer and inner membranes of Gramnegative bacteria. Biochim. Biophys. Acta 1327, 119130 (1997).

67) Tack, B.F.; Sawai, M.V.; Kearney, W.R.; Robertson, A.D.; Sherman, M.A. et al. SMAP-29 has two LPS-binding sites and a central hinge. Eur. J. Biochem. 269, 11811189 (2002).
68) Park, C.H.; Valore, E.V.; Waring, A.J.; Ganz, T. Hepcidin, a urinary antimicrobial peptide synthesized in the liver. J. Biol. Chem. 276, 7806-7810 (2001).

69) In, I.H.; Zhao, C.; Nguyen, T.; Menzel, L.; Waring, A. et $a l$. Clavaspirin, an antibacterial and haemolytic peptide from Styela clava. Chem. Biol. Drug Design 58, 445-456 (2001).

70) Friedrich, C.L.; Moyles, D.; Beveridge, T.J.; Hancock, R.E. Antibacterial action of structurally diverse cationic peptides on gram-positive bacteria. Antimicrob. Agents Chemother. 44, 2086-2092 (2000).

71) Vaara, M.; Vaara, T. Ability of cecropin B to penetrate the enterobacterial outer membrane. Antimicrob. Agents Chemother. 38, 2498-2501 (1994).

72） Tincu, J.A.; Menzel, L.P.; Azimov, R.; Sands, J.; Hong, T. et al. Plicatamide, an antimicrobial octapeptide from Styela plicata hemocytes. J. Biol. Chem. 278, 1354613553 (2003).

73) Epand, R.F.; Lehrer, R.I.; Waring, A.; Wang, W.; MagetDana, R. et al. Direct comparison of membrane interactions of model peptides composed of only Leu and Lys residues. Peptide Sci. 71, 2-16 (2003).

74) Wu, H.; Kuzmenko, A.; Wan, S.; Schaffer, L.; Weiss, A. et al. Surfactant proteins A and D inhibit the growth of Gram-negative bacteria by increasing membrane permeability. J. Clin. Inv. 111, 1589 (2003).

75) Cochrane, C.; Revak, S. Pulmonary surfactant protein B (SP-B): structure-function relationships. Science 254, 566-568 (1991).

76) Ding, L.; Yang, L.; Weiss, T.M.; Waring, A.J.; Lehrer, R.I. et al. Interaction of antimicrobial peptides with lipopolysaccharides. Biochemistry 42, 12251-12259 (2003).

77) Lipp, M.; Lee, K.; Zasadzinski, J.; Waring, A. Phase and morphology changes in lipid monolayers induced by SP-B protein and its amino-terminal peptide. Science 273, 1196-1199(1996). 